\title{
INTERCULTURALIDADE, INTERNACIONALIZAÇÃO E INTERCOMPREENSÃO: QUAL A RELAÇÃO?
}

\author{
Felipe Furtado Guimarães ${ }^{1^{*}}$ \\ Kyria Rebeca Finardi ${ }^{1 * x}$ \\ ${ }^{1}$ Universidade Federal do Espírito Santo, Vitória, Espirito Santo, Brasil
}

\section{Resumo}

Este artigo revisa os conceitos de interculturalidade e internacionalização do ensino superior, discutindo a relação existente entre eles e as línguas adicionais, tecendo algumas considerações sobre o uso de uma abordagem de ensino-aprendizado-uso de línguas adicionais conhecida como abordagem de intercompreensão. A revisão feita aqui conclui que a interculturalidade, a internacionalização e a abordagem de intercompreensão se relacionam na medida em que tanto a interculturalidade quanto a intercompreensão podem servir para mitigar efeitos negativos da internacionalização, tal como o fortalecimento da hegemonia do inglês como língua franca acadêmica.

Palavras-Chave: Interculturalidade; Internacionalização; Intercompreensão.

\section{INTERCULTURALITY, INTERNATIONALIZATION AND INTER- COMPREHENSION: WHAT IS THE RELATION?}

\begin{abstract}
This paper paper reviews the concepts of interculturality and internationalization of higher education, discussing the relationship between them and additional languages, drawing on some considerations on the use of an approach for the teaching-learning-use of additional languages, known as the intercomprehension approach. The review offered here concludes that interculturality, internationalization and intercomprehension are related insomuch as the intercomprehension approach and interculturality can help to mitigate negative effects of internationalization, such as the strengthening of the hegemony of English as the academic lingua franca.

Keywords: Interculturality; Internationalization; Intercomprehension.
\end{abstract}

\footnotetext{
* Doutorando no programa de pós-graduação em Linguística (PPGEL) da Universidade Federal do Espírito Santo (UFES); Mestre em Gestão Pública pela UFES; Licenciado pleno em Letras-Inglês pela UFES; TradutorIntérprete na Secretaria de Relações Internacionais da UFES. Seu e-mail é felipeguim2@yahoo.com.br. ORCID: http://orcid.org/0000-0001-6184-3691.

** Professora do Departamento de Linguagens, Cultura e Educação e dos Programas de Pós Graduação em Linguística (PPGEL) e Educação (PPGE) da Universidade Federal do Espírito Santo (UFES). Seu e-mail é kyria. finardi@gmail.com. ORCID: http://orcid.org/0000-0001-7983-2165.
} 


\section{Introdução ${ }^{1}$}

A redefinição das noções de espaço e tempo, alavancada pelo processo de globalização e pela ampliação do uso de tecnologias de informação e comunicação (TIC), além do desenvolvimento dos transportes, têm impactado o fluxo de informações, mercadorias e pessoas, tal como apontado por Neubauer (2014) e Shin e Teichler (2014), estes últimos se referindo aos impactos no ensino superior.

Nesse contexto, a educação superior passou a ser vista por alguns como uma indústria do conhecimento, indispensável à economia globalizada (YONEZAWA, 2014). Segundo Finardi (2015), a tecnologia tem alterado a maneira como nos expressamos e interagimos com o mundo ao nosso redor, transformando o modo como produzimos e adquirimos informações e conhecimento.

Além disso, as tecnologias permitiram mais acesso à informação, mais "voz" à periferia, mais autonomia na busca por informação e conhecimento e, no caso do uso e ensino-aprendizado de línguas, mais autonomia e possibilidades de interação (FINARDI; PORCINO, 2014). Ainda que a globalização tenha sido associada, no início dos anos 1990, à ideia de prosperidade econômica, Finardi e Porcino (2014) nos lembram que ela também produz efeitos negativos, tal como a "comodificação" da educação, podendo inclusive ser entendida como uma ameaça às culturas locais, ao privilegiar uma "cultura global", eurocêntrica e hegemônica (ANDREOTTI et al., 2015).

A estreita relação entre os termos "globalização" e "internacionalização" faz com que eles sejam vistos como sinônimos (JENKINS, 2014; TEICHLER, 2014) ou como se a internacionalização fosse uma consequência ou agente da globalização. De forma breve, podemos definir a globalização como se referindo ao aumento nas atividades entre fronteiras, com a permanência dessas fronteiras, enquanto que a internacionalização propõe um "apagamento" dessas fronteiras. Knight (2003, p. 2) define internacionalização como "o processo de integrar uma dimensão internacional, intercultural ou global ao propósito, funções ou oferta de educação superior".

A Organização Cultural, Científica e Educacional das Nações Unidas (UNESCO, 2001) considera que o processo de globalização é facilitado pelo desenvolvimento das TIC e, apesar de representar um desafio para a diversidade cultural, cria as condições para um novo diálogo entre culturas e civilizações. A UNESCO afirma que o respeito pela diversidade de culturas, a tolerância, o diálogo e a cooperação, num clima de confiança e entendimento mútuos, podem ser os melhores meios para manter a paz e a segurança internacional. Esse organismo considera cultura como:

[...] um conjunto de características emocionais, intelectuais, materiais e espirituais, que distinguem uma sociedade ou grupo social e que engloba (além da arte e da literatura) os modos de vida e maneiras de viver em grupo, sistemas de valores, tradições e crenças. (UNESCO, 2001) 
A multiplicidade de culturas, línguas e a mobilidade de pessoas têm se tornado o foco de discussões políticas entre Estados, como é o caso da União Europeia, a qual tem dedicado esforços à elaboração de políticas de imigração, ${ }^{2}$ políticas linguísticas ${ }^{3}$ e políticas de internacionalização da educação superior. ${ }^{4}$ Essa multiplicidade representa um desafio para que as diferenças não se tornem um obstáculo nas interações entre diferentes países, povos e culturas.

Tal desafio envolve a questão de relações interculturais, gestão da interculturalidade, gestão da comunicação, comunicação intercultural, negociação de identidades e resolução de conflitos (RAMOS, 2013). A importância da interculturalidade nesse contexto é chave e, por isso, dedicamos este artigo a refletir sobre o papel dela no atual contexto mundial de internacionalização e globalização.

\section{Interculturalidade}

Organismos como a UNESCO elaboraram documentos tais como a "Declaração Universal sobre DiversidadeCultural" em 2001, para tratar da questão da diversidade cultural. Nesse documento a diversidade cultural é mostrada como um patrimônio da humanidade e como fator para desenvolvimento.

Todas as pessoas têm o direito de se expressar e de criar e disseminar seu trabalho na língua de sua escolha, em especial a língua materna; todas as pessoas têm direito à educação de qualidade e formação que respeite plenamente sua identidade cultural; e todas as pessoas têm o direito de participar na vida cultural de sua escolha e de conduzir suas próprias práticas culturais, sujeitas ao respeito pelos direitos humanos e liberdades fundamentais. (UNESCO, 2001)

Cabe destacar que a UNESCO disponibiliza diversos instrumentos legais internacionais sobre cultura, tal como exibido no quadro a seguir.

Quadro 1. Instrumentos legais internacionais da UNESCO sobre cultura

\begin{tabular}{|l|l|}
\hline Ano & Instrumento legal \\
\hline 2007 & Declaração das Nações Unidas sobre os direitos dos povos indígenas \\
\hline 2005 & Convenção sobre a proteção e a promoção da diversidade de expressões culturais \\
\hline 2003 & Convenção sobre a salvaguarda do patrimônio cultural imaterial \\
\hline 2001 & Declaração universal sobre a diversidade cultural \\
\hline 1997 & $\begin{array}{l}\text { Declaração sobre as responsabilidades das gerações presentes em relação às gerações } \\
\text { futuras }\end{array}$ \\
\hline 1972 & Convenção para a proteção do patrimônio mundial, cultural e natural \\
\hline 1970 & $\begin{array}{l}\text { Convenção relativa às medidas a serem adotadas para proibir e impedir a importação, } \\
\text { exportação e transferência de propriedades ilícitas dos bens culturais }\end{array}$ \\
\hline
\end{tabular}

Fonte: Elaborado pelos autores, a partir de dados da página da UNESCO na internet. Disponível em: <http://www.unesco.org/new/pt/brasilia/culture/international-instrumentsclt/>. Acesso em: 31 de maio de 2017. 
A Organização para Cooperação e Desenvolvimento Econômico (OCDE) possui um Observatório da Diversidade Cultural ${ }^{6}$ que é responsável por produzir informação e conhecimento, além de lidar com os desafios de proteger e promover a diversidade cultural. Já a União Europeia possui uma Agência de Direitos Fundamentais que elaborou uma Carta dos Direitos Fundamentais da União Europeia, com um artigo que trata da diversidade cultural, religiosa e linguística, ${ }^{7}$ sob o Título III (Igualdade).

A diversidade e multiplicidade cultural trazem consigo uma "grande heterogeneidade linguística, cultural e comportamental" que exige "práticas, estratégias e políticas" e competências para "gerir a complexidade das relações entre pessoas" (RAMOS, 2013, p. 345). Essa autora indica que no contexto de Portugal criou-se um Plano para Integração de Imigrantes, ${ }^{8}$ que trata de temas como língua, cultura e comunicação, assim como formação para a interculturalidade. Esse plano também trata de questões como o combate à discriminação racial, promoção de diversidade cultural e religiosa e atendimento pelos serviços públicos. Sabemos que o encontro entre culturas é atravessado por "representações sociais, por estereótipos, preconceitos, projeções culturais, ideológicas e políticas" que definem atitudes como aceitação, inclusão, discriminação, exclusão, anulação ou valorização das culturas em interação (RAMOS, 2013, p.347).

O contexto atual mostra que a questão da diversidade cultural e da afirmação das diferenças tem impactado a forma como as nações (e seus indivíduos) lidam com questões globais e locais. Podemos identificar dois movimentos contrários: um centrífugo, no qual a globalização tenta homogeneizar; e outro centrípeto, em que as identidades locais se esforçam por afirmar a heterogenia em um movimento contrário, com ênfase nos valores locais de discursos "nacionalistas", como os recentemente vistos nos Estados Unidos (Donald Trump), no Reino Unido (Brexit) e na França (Marine Le Pen), por exemplo.

A questão dos imigrantes representa a superdiversidade dos tempos contemporâneos. Anteriormente categorizados segundo sua nacionalidade, etnia, língua e religião, agora passam a ser consideradas, na categorização dos migrantes, questões como motivações, padrões, trajetórias e o processo de inserção no mercado de trabalho e na moradia (BLOMMAERT, 2010, apud LIBERALI; MEGALE, 2016, p.96). Assim, a migração não pode ser considerada como equivalente a um "encontro cultural" (RAMOS, 2013, p.348), pois pode ocorrer de forma harmoniosa ou traumática, frequentemente exigindo (mas não necessariamente garantindo) uma ambientação social, psicológica, cultural, histórica e econômica (entre outros aspectos) à nova cultura que o migrante encontra.

Esse processo de aculturação mais ou menos bem-sucedido pode se dar por assimilação, integração, separação ou marginalização (BERRY, 1989). A assimilação se dá quando um grupo (minoritário) se apropria de elementos de outro grupo (majoritário), com a perda de seus padrões culturais de origem, para se adaptar a uma situação desigual entre os grupos; ou seja, o grupo imigrante adota os traços da sociedade que os acolhe. A integração pressupõe a 
conservação parcial da cultura de origem, com participação na nova sociedade. Neste modelo adotam-se valores da cultura nova, mantendo-se valores da cultura de origem. No processo de separação, existe a tentativa de manter a identidade cultural, mantendo a cultura de origem, sem buscar relações com a nova cultura, numa forma de rejeição à cultura dominante. Finalmente, no processo de marginalização, o grupo majoritário impede a participação nas instituições locais, por meio de práticas de discriminação; o migrante perde o direito de participar da vida na nova sociedade e perde sua identidade de origem ao tentar assimilar a nova cultura; assim ele acaba excluído das duas culturas [de origem e a nova] (RAMOS, 2013).

Segundo esse modelo de aculturação, a pressão sobre os migrantes seria maior em sociedades "monoculturais e assimilacionaistas" e menor em sociedades "tolerantes e pluralistas" (RAMOS, 2013, p.349). Essa autora ainda explica que as migrações resultam em mudanças temporais (antes e depois), espaciais (lá e cá), físicas (novo local de residência), biológicas (novas comidas e doenças), sociais (novos padrões e tipos de relações), culturais (educação, língua, religião), psicológicas (motivações e identidades) e políticas (supressão de autonomia).

Segundo Ramos (2013), para transitar e conviver nesse ambiente de diversas culturas, são necessárias algumas competências, dentre as quais destacamos:

- Individuais: permitem interações equilibradas entre indivíduos, com flexibilização e relativização de princípios e modelos, evitando discriminação e intolerância;

- Interculturais: competências linguísticas, de comunicação e pedagógicas; para facilitar o diálogo e a conscientização, promovendo ações inclusivas e educando cidadãos para serem culturalmente sensíveis;

- De cidadania: possibilitam acesso democrático às sociedades e instituições.

Essas competências podem ser mais específicas, como as competências interculturais propostas por Ramos (2013, p.354-355) e que incluem as habilidades de (grifo nosso):

a. Conhecer a si mesmo e sua própria cultura, tendo consciência da própria identidade cultural;

b. Compreender os quadros de referência e os códigos culturais, para ter consciência sobre as características particulares a cada cultura;

c. Desenvolver atitudes como empatia, flexibilidade e interesse por outras culturas, para saber lidar com conflitos, cooperar e negociar; 
d. Entender como os comportamentos são culturalmente determinados, desenvolvendo a habilidade de ver o mundo sob o prisma de outra cultura;

e. Evitar o etnocentrismo, uma inclinação para ver o mundo a partir dos próprios conceitos - isso pode atrapalhar a comunicação e gerar conflitos e desentendimentos;

f. Evitar avaliações rápidas e superficiais, colocando-se no lugar do outro procurar um distanciamento em relação a si mesmo;

g. Aprimorar a empatia;

h. Estar atento aos sinais da comunicação não-verbal - respeitar os estilos de comunicação de cada cultura;

i. Promover formação aos professores no aspecto intercultural - revisar programas e materiais de ensino;

\section{j. Acolher a diversidade linguística existente e favorecer o aprendizado de línguas estrangeiras;}

k. Usar as mídias sociais para conscientizar sobre interculturalidade e enfrentar preconceitos, estereótipos e discriminação;

1. Desenvolver projetos e soluções em conjunto;

m. Conversar com outras culturas e saber negociar, para evitar atitudes de rejeição ou assimilação;

n. Fomentar o desenvolvimento de competências digitais, para promover a comunicação intercultural, permitindo o compartilhamento de ideias, informações e aprendizagem;

Falar de competência intercultural pressupõe antes entender o conceito de cultura. Schoeffel e Gariazzo-Dessiex (2012, p. 4) citam Janet e Milton Bennett, que definem cultura como sendo "o conjunto de crenças, valores e condutas aprendidas, compartilhadas e realizadas por grupos de pessoas em interação". A metáfora do iceberg, que as primeiras usam, ilustra bem a questão a cultura. Tal como o iceberg, que tem uma pequena parte visível e uma grande parte invisível, a cultura também possui aspectos visíveis (alimentos, arquitetura, língua, atitudes não-verbais, arte, sistemas políticos e religiosos, etc.) e invisíveis (valores, crenças e normas). Esses últimos são mais importantes para entender a cultura.

De maneira a desenvolver a competência intercultural, Schoeffel e GariazzoDessiex (2012) propõem a utilização de um Modelo de Desenvolvimento de 
Sensibilidade Intercultural (MDSI), desenvolvido por Bennett (2004). Segundo esse modelo, podemos identificar duas fases no desenvolvimento da sensibilidade intercultural: uma etnocentrista e outra etnorelativista. Na etnocentrista temos a negação, defesa e minimização da cultura enquanto que na etnorelativista o contrário, ou seja, a aceitação, adaptação e integração da cultura do outro. Esse modelo traz uma escala (um contínuo) para classificar como um indivíduo se comportaria em situações de interação intercultural, dependendo do seu posicionamento, mais próximo de sua própria cultura ou mais próximo da cultura de outro.

$\mathrm{Na}$ fase etnocentrista, o indivíduo toma a sua própria experiência cultural como sendo o centro da realidade. Assim, as crenças e comportamentos que as pessoas recebem em sua primeira socialização não são questionados e elas entendem que "o mundo é assim", da maneira que aprenderam quando mais jovens. Já no etnorelativismo as experiências, crenças e comportamentos de um indivíduo são apenas uma forma de organizar a realidade, dentre várias outras possíveis.

Em geral, visões etnocentristas podem ser percebidas como maneiras de evitar a diferença cultural, quer seja negando a existência dessa diferença, levantando as defesas contra essa diferença ou minimizando a importância dessa diferença. Já as visões etnorelativistas são maneiras de alcançar a diferença cultural, quer seja aceitando sua importância, ajustando a perspectiva para considerá-la ou integrando esse conceito na definição de uma identidade (BENNETT, 2004).

Nesse sentido, podemos dizer que ser competente apenas numa área profissional não é suficiente para realizar um trabalho duradouro em um contexto internacional. A competência intercultural é necessária e pode ser aprendida. Schoeffel e Gariazzo-Dessiex (2012) dizem que um profissional competente (do ponto de vista intercultural) sabe usar o conhecimento a respeito de si, da cultura local e das dimensões interculturais, de acordo com cada situação, usando a empatia e gerindo sua ansiedade diante do outro.

Assim a comunicação intercultural é importante não só no contexto de interações internacionais, mas também no contexto local em que sempre há encontros (e desencontros) de culturas. Tendo em vista o papel que as línguas têm na construção de identidades, culturas e realidades, pensamos que elas possam representar um caminho para o desenvolvimento intercultural, abrindo espaço para a tolerância intercultural (EUROPEAN COMMISSION, 2006).

\section{O papel dos idiomas - Plurilinguismo e Intercompreensão}

Segundo Finardi (2014), as línguas adicionais ${ }^{9}$ (L2) são importantes para: 1) manter a coesão nacional (FINARDI; CSILLAGH, 2016); 2) expandir o acesso à informação (FINARDI; PREBIANCA; MOMM, 2013; FINARDI; PORCINO, 2014); 3) expandir o acesso à educação online por meio de cursos online abertos e dirigidos a um público amplo [Massive Online Open Courses - ou MOOC, na abreviação em inglês] (FINARDI; TYLER, 2015); 4) incluir imigrantes e refugiados (ORTIZ; FINARDI, 2015); 5) impulsionar a circulação 
da produção acadêmica mundial (FINARDI; FRANÇA, 2016); e 6) promover a internacionalização crítica da educação superior (FINARDI, 2017b).

A internacionalização da educação e a busca por novas abordagens de ensino e aprendizagem, que possibilitem o acesso a conteúdos educacionais mais amplos e que permitam o desenvolvimento da autonomia do educando, abriram caminho para a oferta de MOOCs que, segundo Finardi (2015), podem ser usados em um formato de "sala de aula invertida". Na abordagem da sala de aula invertida, as atividades que geralmente eram feitas em casa são feitas em sala de aula e viceversa, razão pela qual essa abordagem leva esse nome. Finardi (2015) sugere que no caso do ensino-aprendizado de línguas, a abordagem de sala de aula invertida pode ser usada para potencializar o desenvolvimento de atividades de produção oral e escrita, que passam a ser feitas em sala de aula, enquanto que atividades de compreensão oral e escrita são feitas em casa, aumentando o desenvolvimento da autonomia do educando.

Ao pensarmos no uso de MOOCs para o ensino-aprendizado de línguas no formato invertido, é importante considerar a predominância de universidades anglofalantes que ofertam MOOCs, no ranking Shanghai Jiao Tong University Institute, tal como indicado por Graddol (2006), o qual aponta que cerca de dois terços das 100 universidades melhor posicionadas nesse ranking estão em países anglofalantes. Ainda segundo esse autor, se uma instituição deseja se tornar um centro de excelência internacional, ela precisa atrair estudantes e pesquisadores de diversas partes do mundo, de forma que os estudantes estrangeiros se matriculem em seus cursos, aumentando seu prestígio, suas receitas e criando ali uma "atmosfera intelectual" internacional.

Com esse interesse das universidades em melhorar sua colocação nos rankings da educação superior, tem ocorrido um movimento de "padronização", adotandose um modelo que privilegia a língua inglesa e um padrão de ciência que favorece e assegura um predomínio das universidades "de ponta", provenientes do mundo anglofalante, onde o potencial científico estaria concentrado (MARGINSON, 2014). Além disso, a maior parte da informação na internet estaria disponível na língua inglesa, tal como indicado por Finardi, Prebianca e Momm (2013). No caso dos MOOCs, Finardi e Tyler (2015) apontam que cerca de 85\% deles estão disponíveis apenas em inglês, o que faz com que pessoas que não dominam esse idioma não tenham acesso a esse tipo de conhecimento. Adiciona-se a questão da crise financeira mundial, que tem motivado regiões, como a Escandinávia, a reduzir recursos para o ensino de outras línguas estrangeiras, mantendo apenas os recursos para o ensino de inglês (FINARDI; PORCINO, 2014).

No Brasil, a conversão da Medida Provisória no 746/2016 na Lei no 13.415 de 2017, que tornou o ensino de inglês obrigatório no ensino fundamental, e o lançamento do edital de internacionalização da pós-graduação brasileira, denominado Capes PrInt (também em 2017), o qual prevê o preenchimento de propostas no formulário eletrônico da Capes somente em português e inglês, são duas evidências irrefutáveis de que o Brasil também caminha para o fortalecimento do inglês como língua franca acadêmica. 
Por essa e outras razões, Finardi (2017a) sugere que não é possível falar em multilinguismo sem antes analisar o papel do inglês em relação às outras línguas em determinado contexto. A diversidade linguística e a proficiência em línguas adicionais estão associadas a valores culturais, sociais e econômicos, tal como descrito no documento da Comissão Europeia denominado "Europeus e suas Línguas":

\begin{abstract}
A língua é o caminho para entender outras formas de viver, abrindo espaço para a tolerância intercultural. Além disso, as habilidades linguísticas facilitam trabalhar, estudar e viajar [...] e permitem uma verdadeira comunicação intercultural. Em outras palavras, o multilinguismo contribui [...] para os valores de democracia, igualdade, transparência e competitividade. (EUROPEAN COMMISSION, 2006)
\end{abstract}

Podemos traçar um paralelo entre as estratégias de aculturação de Berry (1989) e os processos de aquisição/aprendizado ${ }^{10}$ de línguas e o modelo de educação bilíngue de Hornberger (1991), no que diz respeito ao acolhimento ou rejeição da nova cultura (língua). Nesse modelo, a aquisição/aprendizado de línguas adicionais e a educação bilíngue podem se dar por meio de um processo de transição, manutenção ou enriquecimento. No primeiro caso, o objetivo da educação bilíngue seria assimilação cultural e incorporação social; usando a língua do aprendiz na instrução até que ele/ela fosse capaz de receber a instrução na língua alvo (língua adicional); valorizando o monolinguismo e permitindo o bilinguismo apenas em caráter temporário. Podemos ver exemplos de transição no Brasil colônia, quando os jesuítas aprendiam um pouco (só o suficiente) de línguas nativas, a fim de poder passar a instrução (e catequização) aos índios em português.

O segundo processo, de manutenção, visa à preservação da língua minoritária, ao passo que os aprendizes desenvolvem a proficiência na língua majoritária; o objetivo cultural é fortalecer a identidade do aprendiz; o objetivo social é confirmar o direito civil de ter uma língua minoritária na escola; as escolas alinhadas com esse modelo se preocupam em manter os valores culturais da comunidade e em incentivar a identidade bicultural nos aprendizes. Podemos ver exemplos de manutenção no Brasil no esforço de alguns municípios do estado do Espírito Santo em co-oficializar o idioma pomerano, ofertando-o nas escolas locais.

O terceiro processo, de enriquecimento, como o próprio nome sugere, não tem como fim subtrair ou minorizar uma cultura/língua em relação à outra, mas antes visa ao desenvolvimento dela. Neste modelo, os aprendizes são ensinados por meio de duas línguas, que geralmente são duas línguas de prestígio; o objetivo cultural é a pluralidade cultural e o objetivo social é a autonomia do aprendiz. Infelizmente não temos muitos exemplos desse processo no Brasil, com raras exceções de escolas bilíngues e internacionais (privadas) onde os conteúdos são ensinados por meio de uma língua adicional (geralmente o inglês), ou de escolas que oferecem instrução em outras línguas além do português, como é o caso de algumas escolas em Aracruz, no Espírito Santo, onde índios recebem 
instrução em guarani e português até a quarta série (quinto ano). Em países onde a pluralidade linguística é reconhecida e garantida, esse processo é mais comum, como no caso do ensino de inglês e francês no Canadá, ou de espanhol, basco e catalão na Espanha.

A fim de garantir o pluri/mutilinguismo no Brasil, Finardi (2017a) sugere o uso de uma abordagem de ensino-aprendizado de línguas conhecida como Abordagem de Intercompreensão [IC] (por exemplo, ARAUJO E SÁ, 2014; CARRASCO PEREA, 2010; TOST PLANET, 2005) que visa desenvolver a compreensão mútua entre diferentes idiomas em interações nas quais pessoas se comunicam em sua própria língua. A IC não é uma alternativa para aprender todas as habilidades de uma língua específica ou uma abordagem para aprender várias línguas ao mesmo tempo, mas uma abordagem multilíngue para desenvolver a compreensão de idiomas adicionais (L2). Do ponto de vista das habilidades linguísticas, a IC implica a conscientização da proximidade linguística, explorando a transparência e a proximidade de elementos linguísticos (lexical, fonológico, morfológico, sintático) para ajudar na compreensão. Esses elementos são muitas vezes subutilizados na maioria das abordagens de ensino L2, devido à tendência de considerar a proximidade linguística mais como um problema para a aprendizagem L2 do que como um recurso que pode auxiliar a aquisição de L2. Um dos principais objetivos da IC é destacar a proximidade entre os idiomas, de modo a aumentar a intercompreensão entre os idiomas que compartilham características comuns em alguns desses elementos. A IC pode ser usada para promover o pluri/multilinguismo em todos os níveis de educação e, por isso, pensamos que essa abordagem possa ser uma alternativa interessante a ser explorada no ensino superior, a fim de estimular uma internacionalização sustentável, com base na interculturalidade.

Em dois estudos realizados numa universidade federal do sudeste brasileiro em relação ao papel das línguas na construção de cidadania e no desenvolvimento da internacionalização, foi concluído que as línguas estrangeiras têm um papel importantíssimo no processo de construção de uma cidadania global que promova a internacionalização, sendo que tais línguas têm que ser garantidas por meio de políticas linguísticas inclusivas e que estimulem o multilinguismo (FINARDI; SANTOS; GUIMARÃES, 2016; FINARDI; GUIMARÃES, 2017).

O processo de aprendizagem de línguas através da IC se mostra eficaz devido a fatores como: o processo de aquisição da competência linguística parte dos conhecimentos que o aprendiz já possui; é uma abordagem que proporciona o desenvolvimento de um trabalho altamente colaborativo entre as línguas, na medida em que aprendizagem se baseia em construções nas quais a língua-fonte e a língua-alvo se correspondem.

Segundo o guia de elaboração de políticas educacionais da Europa (Guide pour lélaboration des politiques éducatives en Europe - BEACCO; BYRAM, 2007), ser plurilíngue implica criar uma competência de utilização de mais de uma variedade linguística. Na mesma direção a carta europeia estabelece o plurilinguismo como 
elemento essencial para inovação científica (OBSERVATÓRIO EUROPEU DO PLURILINGUISMO, 2005).

Considerando que a propagação de informação científica se dá principalmente a partir da produção escrita, a IC pode contribuir de forma satisfatória para o acesso dos estudantes universitários aos conteúdos disponíveis em línguas estrangeiras "aparentadas", pois, ao se ancorar nas similaridades entre essas línguas, permite ao aprendiz adquirir uma habilidade de compreensão escrita na língua(s) estrangeira(s) de maneira autônoma e em curto período de tempo, além de despertar no aprendiz a autoconfiança e o desejo de desenvolver outras habilidades linguísticas, sem falar no combate à hegemonia do inglês e da produção científica dos países anglofalantes antes mencionados.

Martins (2014)apresentadadosdainclusãodadisciplinade“Intercompreensão de Línguas Românicas" na grade curricular do curso de Letras - licenciatura em línguas francesa, inglesa, espanhola e portuguesa, da Universidade do Rio Grande do Norte (UFRN), através da plataforma Galanet, que auxilia a interação entre os aprendizes de universidades estrangeiras. Segundo essa autora, a finalidade da oferta desse curso foi ajudar os alunos no desenvolvimento da consciência plurilíngue e na percepção de que possuem capacidade de aprender línguas, através dos conhecimentos que já possuem em sua língua materna. Nesse sentido, podemos dizer que a IC, por partir dos conhecimentos que os alunos já têm, está, de certa forma, ancorada na teoria sociocultural, que vê o conhecimento sendo construído com base no que o aluno já sabe. Essa teoria também vê o conhecimento como sendo formado por meio da língua, o que apoia o uso de uma abordagem plurilíngue como a IC. Conforme análise da percepção dos alunos que participaram nesse curso desde a implementação da disciplina em 2010, o trabalho tem permitido a compreensão de outras línguas não estudadas anteriormente, além de despertar a curiosidade para o novo.

No relatório elaborado na esfera do lote 7 (Inserção Curricular da Intercompreensão) do projeto MIRIADI (Mutualisation et innovation pour un Réseau de l'Intercompréhension à Distance), Araujo e Sá (2014) apresentam os benefícios ligados à prática da intercompreensão no contexto universitário implicados nesse projeto:

1. A IC como forma de abertura ao plurilinguismo nos contextos educativos em que privilegiam a aprendizagem de uma única língua estrangeira;

2. A IC como valorização dos conhecimentos prévios em línguas;

3. A IC como forma de validação das aquisições teóricas;

4. A IC como forma de promoção do trabalho interdisciplinar e interlinguístico, propondo uma outra representação de ensino e aprendizagem de línguas; 
5. A IC como forma de desenvolvimento das competências tecnológicas em meio pedagógico - a inserção pode ocorrer de forma presencial ou à distância;

6. A IC como forma de abertura a outras línguas e outros universos culturais, principalmente nos casos onde os currículos privilegiam o estudo de uma única língua estrangeira (normalmente o inglês);

7. IC como fator de motivação através do trabalho colaborativo no seio dos grupos multilíngues.

A língua é um dos meios mais importantes e eficazes para o acesso ao outro e, consequentemente, a sua cultura. No contexto de aprendizagem a partir da abordagem de intercompreensão, quanto mais se aprende a língua-alvo, mais se aperfeiçoa a língua-fonte e se desenvolve a sensibilidade e respeito pelas línguas e culturas que entrelaçam o mundo. Num mundo de fronteiras e identidades cada vez mais híbridas (MENDES; FINARDI, 2018), o papel das línguas na construção dessas identidades precisa ser repensado.

\section{Interculturalidade e internacionalização - transferência de modelos educacionais?}

Marmolejo (2010) sugere que uma visão acrítica da internacionalização vê apenas os benefícios desse processo para acadêmicos e instituições, sem questionar por que, como e quem se beneficia desse processo. Ele relata cinco razões principais para a internacionalização, a saber: 1) melhorar a educação; 2) internacionalizar o currículo; 3) melhorar o perfil internacional da instituição; 4) fortalecer a pesquisa e a geração de conhecimento; e 5) diversificar o corpo docente e administrativo da instituição. Todavia, esse autor sugere que as mudanças que estão ocorrendo na educação superior exigem que retiremos os "óculos" tradicionais, para enxergar um novo panorama.

Ao abordar os sistemas educacionais dos países ditos "do Sul" e projetos de cooperação internacional para formação de professores, Akkari e GohardRadenkovic (2008) observam a transferência de modelos educacionais do "Norte" para o "Sul". Eles notam que existe um desalinhamento entre quadros de referência culturais do Norte e do Sul. Além disso, esses autores questionam se a transferência de um modelo (do Norte) seria política e pedagogicamente recomendada, para encontrar soluções reais (e locais) aos desafios educacionais dos países do Sul, criando uma resistência cultural dos países do Sul à importação de modelos educacionais do Norte e às reformas educacionais formuladas no exterior.

Esses autores ainda indicam que o desalinhamento dos contextos tecnológico, econômico, político e cultural entre Norte e Sul desestabiliza as parcerias e acaba por reforçar os estereótipos e desentendimentos culturais. Esse interesse por importação de modelos pode ser explicado por uma tendência dos governantes a 
olhar "para fora", em busca de soluções inovadoras para os problemas educacionais locais. Akkari e Gohard-Radenkovic retomam o modelo de cinco perspectivas de Rose (1991) a respeito de transferência de programas (lesson-drawing11) entre países, que implicam adoção total ou parcial das propostas educacionais. Segundo esse modelo, a transferência educacional pode se dar por um processo de cópia, emulação, hibridização, síntese, inspiração ou empréstimo.

No primeiro processo, podemos notar a adoção, mais ou menos equivalente, de um programa educacional formulado no exterior, sendo que a conjuntura política (e outras variáveis) dos dois contextos mostra alto grau de compatibilidade. Podemos ver exemplos disso no Brasil, com a cópia do sistema educacional português, à época da colonização.

O processo de emulação trata de acomodar as diferenças entre os dois locais, remodelando o programa antes da execução no novo contexto; essa remodelagem permite que o programa transplantado possa estabelecer raízes. Talvez um exemplo desse processo, no nosso contexto, seria o envio de acadêmicos brasileiros para fazer mestrados e doutorados fora do Brasil, sendo que, ao retornar, esses acadêmicos fundam (raízes) programas de pós-graduação aqui, com base no que observaram no exterior.

O terceiro processo, de hibridização, consiste em combinar uma série de elementos, de forma a preparar o programa para o destino final; alguns elementos do programa original podem se tornar inoperantes no novo contexto, mesmo que funcionem no contexto original. No processo de internacionalização, podemos ver essa tendência nos programas de mobilidade acadêmica, nos quais elementos do programa original se tornam inoperantes ou irrelevantes no destino final, como é o caso da validação de créditos estudantis entre instituições de ensino que não possuem acordo de cooperação entre si.

O quarto processo, de síntese, pressupõe a combinação de elementos de diferentes locais para criar um novo programa. Um exemplo desse processo é a oferta de um curso de estudos globais oferecido pela Universidade de Genebra, que reúne elementos de diferentes culturas e áreas do conhecimento, a fim de formar "cidadãos do mundo" (FINARDI, 2017a; FINARDI; CSILLAGH, 2016).

Já no quinto processo, de inspiração, tem-se uma nova perspectiva sobre um problema em comum, que pode inspirar a formulação de um novo programa, sendo que os formuladores podem encontrar tal inspiração na mobilidade acadêmica e por meio de observação, em uma perspectiva indireta. Um exemplo desse processo é citado por Stein et al. (2016) ao descrever um programa para estudantes internacionais no Brasil, para corrigir as origens e efeitos da pobreza existencial.

Finalmente, no último processo, de empréstimo, a apropriação de um modelo educacional (ou reforma) é simplificada; subestimando a especificidade local. Esse formato é o mais frequentemente encontrado, principalmente em instituições privadas com fins lucrativos, como as franquias de escolas e campi de universidades norte-americanas e inglesas na Ásia e no Oriente Médio.

Podemos traçar um paralelo entre essas perspectivas e as propostas de Berry (1989) para a aculturação e de Hornberger (1991) para a educação bilíngue, no 
sentido em que há uma tensão presente na negociação (ou imposição) entre valores globais e locais.

Assim, Akkari e Gohard-Radenkovic (2008) questionam: O que é uma política de transferência? Quem realiza a transferência? Por que uma política é transferida, e a partir de que aprendizado ela é implantada? Por que se toma emprestado um modelo educacional e quais as consequências locais desses empréstimos? Parte das respostas está nas partes interessadas (stakeholders) nesse processo, conforme esses autores destacam: os políticos, os partidos, os burocratas, os grupos de pressão, os especialistas, os empresários e as instituições supranacionais.

Phillips (2000, apud AKKARI; GOHARD-RADENKOVIC, 2008) indica sete estágios para a transferência de um modelo educacional:

a. Acumulação: atividade de reunir ideias, por aqueles capazes de inseri-las na arena política, no momento certo;

b. Incubação: fase na qual as ideias ou políticas adentram o âmbito dos tomadores de decisão, mas ainda não foram absorvidas pelo governo;

c. Assimilação: surgimento de uma opção, favorecida nos documentos oficiais sobre políticas;

d. Tradução: definição dos detalhes da política, como parte da agenda de ação;

e. Contextualização: promulgação da nova política e tentativa de integração ao contexto local;

f. Refração: consequências da tentativa de contextualização, tais como a resistência e como os desafios são tratados, podendo resultar em alterações na política;

g. Resolução: integração da política importada ao novo ambiente; pode não ocorrer como fora planejado, inclusive até com o abandono da política importada e adoção de uma outra opção.

Tendo em vista essas etapas, Akkari e Gohard-Radenkovic (2008) indicam uma dificuldade estrutural na cooperação: a desigualdade entre as partes. Desigualdade essa que se manifesta em diferentes níveis: organizacional, financeiro, tecnológico e de (insta)estabilidade. Um exemplo disso são projetos em que a (falta de) infraestrutura local, como o acesso à internet, pode prejudicar as cooperações entre países. Um outro exemplo é a diferença de formação pedagógica, como no caso do Brasil (super-politizada) e da Suíça (sub-politizada). Outro exemplo seriam os usos de línguas - geralmente a língua do parceiro mais forte (do Norte) é a utilizada para comunicação e trabalho. 
Assim, corroborando as proposições de Ramos (2013), Akkari e GohardRadenkovic (2008) explicam que, no contexto de cooperações internacionais, o uso de estereótipos acaba exprimindo uma tendência ao etnocentrismo - uma visão de "normalidade" de "nossas" práticas de ensino/pesquisa e uma "anormalidade" das práticas dos "outros". Tais estereótipos acabam exercendo uma função ideológica, relacionada a conflitos e a discriminações reais, ou ao que Andreotti et al. (2015) chamam de "violência" no processo de internacionalização.

Nesse contexto de interações entre culturas, notam-se mudanças no ensino superior, com a pressão que as universidades vêm sofrendo para se internacionalizar (ou se "normalizar", segundo o padrão etnocentrista). Uma das formas mais evidentes desse movimento é a implantação de campi do tipo offshore (fora de seus países de origem), que nos obriga e refletir sobre o papel do ensino superior, seja ele de serviço público ou de commodity, como já alertado por Finardi e Porcino (2015) sobre um dos efeitos negativos da globalização (comodificação da educação) e por Finardi (2014), no caso específico do ensino de inglês no Brasil.

Ao tratar desse movimento, Akkari (2011, p. 7) cita Altbach, Reisberg e Rumbley (2009) para explicar que a internacionalização pode ser definida como sendo "o conjunto de políticas e programas que os governos e as universidades põem em prática para lidar com a globalização e massificação do ensino superior". Isso envolve enviar alunos/professores para mobilidade no exterior, estabelecer parcerias entre instituições, ou mesmo estabelecer um campus descentralizado em outro país (AKKARI, 2011). Nesse processo, o setor de educação adota estratégias para lidar com desafios como a quantidade insuficiente de vagas em determinadas áreas e a disputa pelas melhores instituições, embarcando numa disputa por uma classificação e reconhecimento internacional. Esse autor ainda afirma que existe concorrência para obter financiamento para pesquisa, resultando num declínio do engajamento das universidades com as comunidades locais, colocando em risco a tradição da universidade como um serviço público e os seus valores éticos.

Ao tratar do estabelecimento de filiais de universidades fora de seus países de origem, Akkari (2011) indica que uma das motivações para que os países recebam universidades estrangeiras é a busca por qualidade de uma educação "vinda de fora". Outro motivo seria a abertura dos mercados para serviços de educação, seguindo recomendações da Organização Mundial do Comércio (OMC), acompanhando as tendências promovidas pela globalização.

Empresas do setor educacional buscam então se beneficiar da abertura promovida por acordos internacionais, tal como acontece nos Estados Unidos, Reino Unido, Austrália e Canadá, que figuram entre os países que mais recebem estudantes estrangeiros (DEPARTMENT OF COMMERCE, 2016). No caso da Nova Zelândia, a educação é considerada um dos itens mais exportados por aquele país, segundo Ball e Youddel (2007). Não podemos nos furtar de fazer uma observação aqui, já feita anteriormente em outros trabalhos (por exemplo FINARDI; SANTOS; GUIMARÃES, 2016), de que há uma "coincidência" entre esses países e a língua 
falada neles. Se observamos esses dados dessa forma, veremos que Hamel (2013) tinha razão ao afirmar que existe uma correlação entre a língua inglesa e a direção na qual a educação é exportada (e importada). Indo na mesma direção e tratando especificamente da globalização e da internacionalização, Vavrus e Pekol (2015) afirmam que há outra "coincidência" também no grupo de países beneficiados por esses dois processos. Na visão desses autores, o Norte (especialmente o anglófono) se beneficia muito mais da internacionalização do que o Sul.

Ao tratar das modalidades de interação entre instituições ocidentais e universidades de países da região do Golfo, Willoughby (2008) define cinco tipos de instituições que foram implantadas naquela região, quais sejam, as oriundas de uma associação simbólica, as oriundas de uma supervisão formal, as de endosso formal, as de subcontratação e as sucursais.

Nas primeiras, a universidade local solicita consultoria aos gestores da instituição ocidental e indica, de maneira ampla, como seu programa pode ser similar ou modelado de acordo com o parceiro estrangeiro. Nas segundas, a universidade local estabelece uma parceria formal com a instituição estrangeira que se compromete a desenvolver e monitorar programas específicos ou todos os programas acadêmicos de uma nova universidade. Nas terceiras, semelhantemente ao que ocorre no modelo de supervisão formal, a instituição ocidental fornece serviços de credenciamento à universidade local, da mesma forma como fornece esses serviços para outras instituições ocidentais, sendo que a aprovação da universidade local no credenciamento sugere que os cursos ali oferecidos são comparáveis àqueles ofertados nas instituições ocidentais. No modelo de subcontratação, a instituição ocidental fornece pessoal administrativo e professores à universidade local, que é uma entidade administrativa independente e contrata seus próprios funcionários, mas solicita a supervisão (parcial ou integral) da instituição ocidental. Finalmente, no modelo de sucursal, que é uma versão mais intensa do modelo de subcontratação e, diferentemente dos modelos anteriores, os empreendedores educacionais locais não criam uma universidade ligada a instituições ocidentais; em vez disso, a instituição ocidental é convidada a abrir uma sucursal fora de seu país de origem, com autorização para conceder um grau em nome da matriz; a instituição ocidental assume a responsabilidade por todas as fases principais da gestão da universidade (exceto, talvez, pela construção e manutenção das instalações físicas) e recebe um pagamento por isso.

Essa tipologia de instituições pode demonstrar o grau de intensidade com que instituições estrangeiras e locais interagem, para ofertar educação superior no contexto local. Todavia, segundo Akkari (2011), pode ser que os laços que as instituições estrangeiras estabelecem com o contexto cultural local sejam fracos ou mesmo inexistentes.

No Brasil, Finardi e Ortiz (2015) investigaram a motivação para internacionalização de duas universidades, uma pública, e outra privada. Com base em estudos sobre a internacionalização na Europa, os autores partiram da hipótese de que uma das motivações para a internacionalização era o desejo 
de atrair recursos externos (por meio de cobrança de mensalidades de alunos estrangeiros) para a instituição nacional. Resultados desses estudos rejeitaram completamente essa hipótese, já que a instituição pública não tinha fins lucrativos e a instituição privada, que poderia ter, não tinha motivação para a internacionalização. Os autores explicaram esse resultado inesperado com base no número de instituições públicas versus privadas no Brasil. Segundo Finardi e Ortiz (2015), o número de instituições públicas é cerca de um terço do número das privadas, o que faz com que o mercado interno para as instituições privadas seja muito confortável no Brasil, já que as universidades privadas daqui não precisam recrutar alunos estrangeiros, em um país com mais de 200 milhões de habitantes, em que apenas um terço deles consegue estudar gratuitamente em instituições públicas.

No mesmo sentido e em um estudo comparativo entre a realidade de universidades na Turquia e no Brasil, Taquini, Amorim e Finardi (2017) viram que essa proporção entre universidades públicas e privadas é o inverso na Turquia, o que explica em parte o fenômeno das aulas ofertadas em inglês (English Medium Instruction - ou EMI, na abreviação em inglês) nas instituições de ensino superior turcas, como uma estratégia para serem aceitos pela Comunidade Europeia. Pensamos ser importante pensar num modelo com mais equilíbrio entre universidades públicas e privadas e acordos e parcerias entre Norte e Sul, tal como propõem esses autores (HAMEL, 2013; VAVRUS; PEKOL, 2015; FINARDI; SANTOS; GUIMARÃES, 2016).

Akkari (2017) comenta que o Brasil ainda não tem recebido uma "invasão" de instituições estrangeiras porque ainda não teria assinado o tratado da Organização Mundial do Comércio (OMC) que lida com a "mercantilização" da educação superior e cujo Acordo Geral sobre Comércio e Serviços (GATS, na sigla em inglês), impulsionado pelo processo de globalização e influenciado pelo neoliberalismo, tem agido para beneficiar o setor privado (NEUBAUER, 2014). Assim, fornecedores privados de serviços de educação têm buscado inserção no mercado internacional, por meio de novos formatos institucionais, derivados de modelos das empresas transnacionais.

Parte desse movimento de privatização da educação superior pode ser explicada pela situação ruim das finanças públicas, que levam os Estados a limitar o investimento público nesse setor. Cabe destacar que o custo da educação superior é muito maior do que o custo da educação fundamental e secundária, o que torna a educação superior mais sensível a fatores econômicos (SHIN; KIM, 2014). Ainda assim, o poder público tem um papel fundamental nas políticas educacionais, em especial no que se refere ao fluxo de estudantes e mecanismos de controle de qualidade (AKKARI, 2011).

Hannon (2013) diz que, ao redor do mundo, as pressões sobre as instituições tem aumentado, por conta da globalização, mobilidade social, tecnologias de comunicação, questões geopolíticas e demográficas e pressões econômicas, para que os governos reavaliem seus investimentos nos serviços financiados pelo Estado, incluindo a educação superior. Lee et al. (2014) descrevem o momento 
que as universidades têm passado como sendo o surgimento do "capitalismo acadêmico", em que serviços gratuitos têm sido substituídos por serviços pagos.

Cada vez mais, vê-se que a educação tem sido submetida às pressões da lógica do mercado, razão pela qual pensamos que o Estado deveria interferir no sentido de não permitir que desigualdades sociais determinem as chances de acesso à universidade, atuando de forma a repensar as relações entre a esfera política e o setor privado (AKKARI, 2011), considerando a universidade um bem público (SHIN, 2014).

Com o apagamento de fronteiras entre o público e o privado, Ball e Youdell (2007) tipificam a privatização da educação pública em "privatização endógena" e "privatização exógena". A primeira (endógena) é uma forma de privatização que implica a importação de ideias, técnicas e práticas advindas do setor privado, para que o setor público se torne mais receptivo ao "espírito empresarial", a fim de funcionar de forma semelhante a uma empresa. A segunda (exógena) implica uma abertura dos serviços públicos a uma participação do setor privado ou utiliza o setor privado para conceber certos aspectos da educação pública. Nesse cenário, caberia ao Estado intervir para que a situação das instituições públicas de ensino superior não se deteriore, diante da lógica do mercado.

Interculturalidade, internacionalização e intercompreensão: qual a relação?

Como podemos ver do exposto até aqui, a interculturalidade, a internacionalização do ensino superior e a abordagem de intercompreensão se relacionam no contexto hodierno, na medida em que a internacionalização tem reforçado a hegemonia do inglês e da produção científica anglofalante, enquanto que a interculturalidade e a abordagem de intercompreensão podem servir para combater essa hegemonia, ampliando o acesso à educação/informação e aumentando a sensibilidade intercultural e a integração mundial, de forma mais pacífica e justa. A abordagem da intercompreensão, se usada em consonância com a noção mais abrangente de interculturalidade, pode servir para aumentar a sensibilidade e a proximidade entre línguas, povos e culturas.

Pensamos que o processo de internacionalização brasileiro, induzido por editais como o Capes PrInt e por programas como o extinto "Ciências sem Fronteiras", pode se beneficiar de uma visão mais ampla, crítica, intercultural e multilíngue, por meio de abordagens mais inclusivas, como a de intercompreensão, e por meio da promoção de políticas linguísticas e de internacionalização mais inclusivas. Assim, línguas que foram desfavorecidas, por conta de alterações recentes na legislação brasileira, podem ter possibilidades de coexistir com o inglês, o qual tem sido amplamente adotado em diversas instâncias, quer sejam acadêmicas, culturais, científicas, comerciais, entre outras. Ao propormos uma atitude mais ativa e reflexiva, em resposta às mudanças trazidas pela globalização e internacionalização, esperamos despertar a atenção para possibilidades que auxiliem a lidar com a tensão entre valores locais e globais e com as diferenças culturais. 


\section{Agradecimentos}

Este estudo foi parcialmente apoiado pela Fapes (Edital Universal 03/2017, autor 2).

\section{Notes}

1. Com a finalidade de ampliar as discussões para além do idioma inglês, em se tratando da temática intercultural, este artigo teve contribuição de uma licenciada em Letras-Francês, Nathielli Souza Moreira, da Universidade Federal do Espírito Santo (UFES).

2. Política Conjunta de Imigração para a Europa [União Europeia]. Disponível em: <http://eur-lex.europa.eu/legal-content/EN/TXT/?uri=URISERV:j10001>. Acesso em: 26 de maio de 2017.

3. Política Linguística Europeia [Parlamento Europeu]. Disponível em: $<\mathrm{http} / / / \mathrm{www}$. europarl.europa.eu/atyourservice/en/displayFtu.html?ftuId=FTU_5.13.6.html $>$. Acesso em: 26 de maio de 2017.

4. Política de Internacionalização da Educação Superior [Parlamento Europeu]. Disponível em: <http://www.europarl.europa.eu/RegData/etudes/ STUD/2015/540370/IPOL_STU(2015)540370_EN.pdf>. Acesso em: 26 de maio de 2017.

5. Disponível em: <http://portal.unesco.org/en/ev.php-URL_ID=13179\&URL_ DO=DO_TOPIC\&URL_SECTION=201.html>. Acesso em: 26 de maio de 2017.

6. Disponível em: $<$ http://observatoriodadiversidade.org.br/site/tag/ocde/ $>$. Acesso em: 26 de maio de 2017

7. Disponível em: <http://fra.europa.eu/pt/charterpedia/article/22-diversidade-cul tural-religiosa-e-linguistica $>$. Acesso em: 26 de maio de 2017.

8. Disponível em: $<$ https://ec.europa.eu/migrant-integration/index.cfm?action=me dia.download\&uuid=2A20756E-B470-4CFB-D60C8358F8A5A630>. Acesso em: 31 de maio de 2017.

9. Neste artigo o termo "língua adicional" se refere a outra língua que não seja a língua materna.

10. Entendemos que há uma diferença entre os termos "aquisição" e "aprendizado" de línguas. Enquanto o primeiro se refere ao processo que ocorre naturalmente com nossa língua materna, o segundo se refere ao processo formal de instrução, com vistas a levar o estudante a aprender uma língua adicional. Entretanto, para os fins deste estudo, e a menos que expressamente mencionado, iremos nos referir a esses dois termos como sendo intercambiáveis, uma vez que a distinção não é necessária para o escopo do tema tratado aqui.

\section{Referências}

AKKARI, Abdeljalil. Desenvolvimento de competências interculturais e cooperação universitária internacional: Comunicação pessoal apresentada em curso promovido pelo Grupo Coimbra de Universidade Brasileiras (GCUB), na Universidade de Brasília. Abril de 2017. 2011.

L'internationalisation de l'enseignement superieur. Education Permanente.

AKKARI, Abdeljalil; GOHARD-RADENKOVIC, Aline. Coopération internationale: entre accommodements interculturels et utopies du changement. Paris: Harmattan, 2008. 
ANDREOTTI, Vanessa de Oliveira; STEIN, Sharon; AHENAKEW, Cash; HUNT, Dallas. Mapping interpretations of decolonization in the context of higher education. Decolonization: Indigeneity, Education \& Society, v. 4, n. 1, p.21-40, 2015.

ARAUJO E SÁ, Maria Helena. Atouts et possibilités de l'insertion curriculaire de l'intercompréhension. Report published in the Miriadi project. Disponível em: $<$ https://www.miriadi.net/sites/default/files/prestation_7-1.pdf >. Acesso em: 18 jul. 2017. 2014.

BALL, Stephen J.; YOUDELL, Deborah. La privatisation déguisée dans le secteur éducatif public. In: INTERNATIONALE DE L'ÉDUCATION. 5éme Congrès Mondial. Julho de 2007.

BEACCO, Jean Claude; BYRAM, Michael. Le Conseil de l'Europe et les politiques linguistiques éducatives : le plurilinguisme comme principe fondateur. In: Guide pour lélaboration des politiques linguistiques éducatives en Europe, Conseil de l'Europe, Division des Politiques linguistiques, Strasbourg, 2007. p. 32-42.

BENNETT, Milton J. Becoming interculturally competent. In: WURZEL, J.S. (Org.). Toward multiculturalism: a reader in multicultural education. Newton, MA: Intercultural Resource Corporation, 2004.

BERRY, John W. Acculturation et adaptation psychologique. In: RETSCHITZKY, J.; BOSSEL, M.; DASEN, P. (Orgs.) La recherche psychologique. Paris: Hamarttan, 1989. p.135-145.

CARRASCO PEREA, Encarnacion. Intercompréhension (s): repères, interrogations et perspectives. Synergies Europe 5. Disponível em: <https://gerflint.fr/Base/ Europe5/introduction.pdf>. Acesso em: 18 jul. 2017. 2010.

DEPARTMENT OF COMMERCE. United States of America. International Trade Administration. 2016 Top Markets Report: Education. 2016. Disponível em: $<$ http://trade.gov/topmarkets/pdf/Education_Executive_Summary.pdf $>$. Acesso em: 6 jun. 2017.

EUROPEAN COMMISSION. Europeans and their languages. Special Eurobarometer 243. Fevereiro de 2006.

FINARDI, Kyria Rebeca. Current trends in ELT and affordances of the inverted CLIL approach. Studies in English language teaching. v. 3, n.4, 2015.

FINARDI, Kyria Rebeca. Internacionalização crítica: possibilidades para a inclusão e (in)formação superior. A educação docente em contextos de internacionalização/ mundialização: Mesa apresentada em I Jornada Internacional de Linguística Aplicada Crítica: A Linguística Aplicada Crítica e seu Compromisso com a Sociedade. Universidade de Brasília, 24 e 25 de abril de 2017b.

FINARDI, Kyria Rebeca. The Slaughter of Kachru's Five Sacred Cows in Brazil: Affordances of the Use of English as an International Language. Studies in English Language Teaching. v. 2, 2014. p. 401-411.

FINARDI, Kyria Rebeca. What Brazil can learn from Multilingual Switzerland and its use of English as a Multilingua Franca. Acta Scientiarum (UEM), v. 39, p. 219228, 2017a.

FINARDI, Kyria Rebeca; CSILLAGH, Virag. Globalization and linguistic diversity in Switzerland: insights from the roles of national languages and English as a foreign language. In: GRUCZA, Sambor; OLPINSKA-SZKIELKO, Magdalena; ROMANOWSKI, Piotr. (Orgs.). Advances on understanding multilingualism: a global perspective. Frankfurt am Main: Peter Lang Edition, 2016. 
FINARDI, Kyria Rebeca; FRANÇA, Claudio. O inglês na internacionalização da produção científica brasileira: evidências da subárea de Linguagem e Linguística. Intersecções. Jundiaí, ed. 19, ano 9, n. 2, p. 234-250. 2016.

FINARDI, Kyria Rebeca; GUIMARÃES, Felipe Furtado. Construindo Cidadania Por Meio da Língua e da Internacionalização. Revista Guará, v. 5, p. 35-46, 2017.

FINARDI, Kyria Rebeca; ORTIZ, Ramón Andrés. Globalization, Internationalization and Education: What is the Connection? IJAEDU- International E-Journal of Advances in Education. v. 1, p. 18-25, 2015.

FINARDI, Kyria Rebeca;PORCINO, Maria Carolina daSilva. Tecnologiaemetodologia no ensino de inglês: impactos da globalização e da internacionalização. Ilha do Desterro. Florianópolis, n. 66, p. 239-282. 2014.

FINARDI, Kyria Rebeca; PREBIANCA, Gicele Vergine; MOMM, Christiane Fabiola. Tecnologia na educação: o caso da internet e do inglês como linguagens de inclusão. Cadernos do IL, Porto Alegre, n. 46, p.193-208. Junho de 2013.

FINARDI, Kyria Rebeca; SANTOS, Jane Meri; GUIMARÃES, Felipe Furtado. A relação entre línguas estrangeiras e o processo de internacionalização: evidências da coordenação de letramento internacional de uma universidade federal. Interfaces Brasil/Canadá. Pelotas, v. 16, n. 1, p. 233-255. 2016.

FINARDI, Kyria Rebeca; TYLER, Jhamille. The role of English and technology in the internationalization of education: insights from the analysis of MOOCs. In: International Conference on Education and New Learning Technologies. EduLearn 15 Proceedings. Barcelona: IATED, 2015. p. 11-18.

GRADDOL, David. English Next: why global English may mean the end of "English as a foreign language". British Council, 2006.

HAMEL, Rainer. 2013. L’anglais, langue unique pour les sciences? Le rôle des modèles plurilingues dans la recherche, la communication scientifique et l'enseignement supérieur. Synergies Europe, (8), 53-66.

HANNON, Paul D. Why is the entrepreneurial university important? Journal of innovation management, v. 1, n. 2, p.10-17, 2013.

HORNBERGER, Nancy H. Language planning and internationalism. Planning for higher education. 19(3), p.11-21. 1991.

JENKINS, Jennifer. English as a lingua franca in the international university: the politics of academic English language policy. Nova Iorque: Routledge, 2014.

KNIGHT, Jane. Updating the definition of internationalization. International Higher Education. The Boston College Center for International Higher Education. n. 33. 2003.

LEE, Jenny J.; TORRES-OLAVE, Blanca; KOLLASCH, Aurelia; RHOADES, Gary. University service: conceptions and enactments of university service in the knowledge economy case studies from faculty in the USA. In: SHIN, Jung Cheol; TEICHLER, Ulrich. (Orgs.). The future of the post massified university as the crossroads. Nova Iorque: Springer, 2014. p.119-141.

LIBERALI, Fernanda Coelho; MEGALE, Antonieta. Elite bilingual education in Brazil: an applied linguist's perspective. Colombian Applied Linguistics Journal, v. 18, n. 2, 2016, p.95-108.

MARGINSON, Simon. University research: the social contribution of university research. In: SHIN, Jung Cheol; TEICHLER, Ulrich. (Orgs.). The future of the post massified university as the crossroads. Nova Iorque: Springer, 2014. p.101-117. 
MARMOLEJO, Francisco. Internacionalización de la educación superior: lo bueno, lo malo y lo inesperado. The Chronicle of Higher Education. Outubro de 2010, p.2.

MARTINS, Selma Alas. A intercompreensão de línguas românicas: proposta propulsora de uma educação plurilíngue. MOARA - Revista Eletrônica do Programa de Pós-Graduação em Letras, n. 42, p. 117-126, jul/dez. 2014.

MENDES, Ana Rachel Macedo; FINARDI, Kyria Rebeca. Linguistic Education Under Revision: Globalization and EFL Teacher Education in Brazil. Education and Linguistics Research, v. 4, p. 45-64, 2018.

NEUBAUER, Deane. The university in the context of continuing globalization. In: SHIN, Jung Cheol; TEICHLER, Ulrich. (Orgs.). The future of the post massified university as the crossroads. Nova Iorque: Springer, 2014. p.29-43.

OBSERVATÓRIO EUROPEU DO PLURILINGUISMO. Carta Europeia do Plurilinguismo. 2005. Disponível em: <http://e-ipol.org/wp-content/ uploads/2013/04/Carta_Europeia_do_Plurilinguismo.pdf >. Acesso em: 15 de jul. 2017.

ORTIZ, Ramón Andrés; FINARDI, Kyria Rebeca. Social Inclusion and CLIL: Evidence from La Roseraie. In: International Conference on Education, Research and Innovation 2015, Sevilha. ICERI2015 Proceedings. Madri: IATED, 2015. v. 1. p. $7660-7666$.

RAMOS, Natália. Interculturalidade(s) e mobilidade(s) no espaço europeu: viver e comunicar entre culturas. The overarching issues of the European space. Porto: Editora da Faculdade de Letras da Universidade do Porto, 2013. p.343-360.

ROSE, Richard. What is lesson drawing? Journal of public policy. v. 11, p.3-30. 1991.

SCHOEFFEL, Véronique; GARIAZZO-DESSIEX, Françoise. Competencia intercultural en la cooperación internacional. CINFO (Centre d'information, de conseil et de formation pour les professions de la coopération internationale). 2012.

SHIN, Jung Cheol. The university as an institution of higher learning: evolution or devolution? In: SHIN, Jung Cheol; TEICHLER, Ulrich. (Orgs.). The future of the post massified university as the crossroads. Nova Iorque: Springer, 2014. p.13-27.

SHIN, Jung Cheol; KIM, Yangson. Economic crises and the post-massification of higher education. In: SHIN, Jung Cheol; TEICHLER, Ulrich. (Orgs.). The future of the post massified university as the crossroads. Nova Iorque: Springer, 2014. p.45-57.

SHIN, Jung Cheol; TEICHLER, Ulrich. The future of the post massified university as the crossroads. Nova Iorque: Springer, 2014.

STEIN, Sharon; ANDREOTTI, Vanessa; BRUCE, Judy; and SUŠA, Rene. Towards Different Conversations about the Internationalization of Higher Education. Comparative and International Education / Éducation Comparée et Internationale. v. 45, ed. 1, artigo 2. 2016. Disponível em: < http://ir.lib.uwo.ca/cie-eci/vol45/ iss $1 / 2>$. Acesso em: 20 maio 2017.

TAQUINI, Reninni; FINARDI, Kyria Rebeca; AMORIM, Gabriel. English as a Medium of Instruction at Turkish State Universities. Education and Linguistics Research, v. 3, p. 35-53, 2017.

TEICHLER, Ulrich. Higher education and the future social order: equality of opportunity, quality, competitiveness? In: SHIN, Jung Cheol; TEICHLER, Ulrich. (Orgs.). The future of the post massified university as the crossroads. Nova Iorque: Springer, 2014. p.183-203. 
TOST PLANET, Manuel Antonio. Les projets européens d'intercompréhension entre locuteurs de langues romanes. Disponível em: <http://lingalog.net/dokuwiki/_ media/intercomprehension/rcslr/chapitre2_livre_benucci.pdf $>$. Acesso em: 18 jul. 2017. 2005.

UNESCO. Declaração Universal sobre a Diversidade Cultural (2001). Disponível em: < http://portal.unesco.org/en/ev.php-URL_ID=13179\&URL_DO=DO_ TOPIC\&URL_SECTION=201.html>. Acesso em: 26 maio 2017.

VAVRUS, Frances; PEKOL, Amy. 2015. Critical Internationalization: Moving from Theory to Practice, FIRE: Forum for International Research in Education: 2: (2), Disponível em: $<$ http://preserve.lehigh.edu/;re/vol2/iss2/2>. Acesso em: 26 maio 2017.

WILLOUGHBY, John. Let a thousand models bloom: forging alliances with western universities and the making of the new higher education system in the Gulf. Department of Economics: working paper series. Washington DC: American University, 2008, p. 16-19.

YONEZAWA, Akiyoshi. The internationalization of the university as a response to globalization: an east Asian perspective. In: SHIN, Jung Cheol; TEICHLER, Ulrich. (Orgs.). The future of the post massified university as the crossroads. Nova Iorque: Springer, 2014. p. 59-71.

Recebido em: 28/07/2017

Aceito em: 09/04/2018 